ISSN 2525-4804

\title{
PERDAS ECONÔMICAS DECORRENTES DE LESÕES EM CARCAÇAS BOVINAS DURANTE O TRANSPORTE PRÉ-ABATE: O CASO DO ESTADO DO TOCANTINS
}

\author{
Alessandra Polastrini ${ }^{1}$, Lilian dos Santos Fontes Pereira Bracarense ${ }^{2}$, Manoel Xavier Pedroza Filho ${ }^{3}$
}

\section{RESUMO:}

A bovinocultura de corte é uma das atividades econômicas mais importantes do estado do Tocantins. Todavia, perdas econômicas são atribuídas ao transporte dos bovinos até o abate. O objetivo da pesquisa foi estimar as perdas econômicas decorrentes do descarte de lesões nas carcaças bovinas causadas pelo transporte pré-abate no estado do Tocantins. A pesquisa foi realizada por meio de pesquisa bibliográfica e documental e 21 entrevistas semiestruturadas. As estimativas apontaram perdas econômicas em função da retirada de lesões nas carcaças que vão de $\mathrm{R} \$ 179.907,00$ a $\mathrm{R} \$$ 32.383.200,00 anualmente. Para produtores perdas ocorrem devido a retirada de lesões, reduzindo o rendimento de carcaça e o valor recebido por animal abatido. Para frigoríficos, quando apenas no processamento se detectam lesões. Para consumidores, são percebidas apenas no momento do preparo da carne. Falta capacitação dos atores profissionais que trabalham com o transporte de bovinos sobre os impactos do transporte à cadeia. Estudos futuros são sugeridos com o intuito melhorar capacitação dos atores desses profissionais.

Palavras-chave: bem-estar animal, carcaças, motorista, veículo.

\section{ECONOMIC LOSSESARISING FROM INJURIES IN BOVINE CARCASES DURING PRE- SLAUGHTER TRANSPORT: CASE OF THE STATE OF TOCANTINS}

\begin{abstract}
:
Beef cattle is one of the most important economic activities in the state of Tocantins. However, economic losses are attributed to the transport of cattle until slaughter. The objective of the research was to estimate the economic losses resulting from the disposal of lesions in bovine carcasses caused by pre-slaughter transport in the state of Tocantins. The research was carried out through bibliographic and documentary research and 21 semi-structured interviews. Estimates pointed to economic losses due to the removal of lesions in the carcasses, ranging from R \$ $179,907.00$ to $\mathrm{R} \$ 32,383,200.00$ annually. For producers, losses occur due to the removal of lesions, reducing the carcass yield and the amount received per slaughtered animal. For refrigerators, when only processing is detected lesions. For consumers, they are perceived only when preparing meat. The actors lack training on the impacts of transportation to the chain. Future studies are suggested in order to improve the training of the actors.
\end{abstract}

\footnotetext{
${ }^{1}$ Zootecnista, Doutoranda em Desenvolvimento Regional, Universidade Federal do Tocantins, Palmas - TO. alessandra.polastrini@mail.uft.edu.br

${ }^{2}$ Enga . Civil, Dra. em Transportes, Universidade Federal do Tocantins, Plamas - TO. lilianfontes@mail.uft.edu.br

${ }^{3}$ Eng. Agrônomo, Dr. em Economia, Embrapa/Universidade Federal do Tocantins, Palmas - TO. manoel.pedroza@embrapa.br 
Revista Agri-Environmental Sciences, Palmas-TO, v. 7, e021001, 2021

DOI: https://doi.org/10.36725/agries.v7i1.4146

ISSN 2525-4804

Key words: animal well-being, carcasses, driver, vehicle. 


\section{INTRODUÇÃO}

A criação de bovinos de corte é uma importante atividade econômica para o Brasil. Em 2019 o PIB pecuária de corte apresentou crescimento, passando a representar $8,5 \%$ do PIB total (ABIEC, 2020). Em termos nominais foi registrado um crescimento de $3,5 \%$ no PIB da pecuária de corte, pois esta movimentou 618,50 bilhões de reais em 2019 (ABIEC, 2020).

O rebanho bovino brasileiro alcançou os 213,68 milhões de cabeças, registrando um abate de 43,3 milhões delas, número que revelou um aumento de $12,2 \%$ nas exportações sendo $23,6 \%$ do volume total destinado ao mercado externo, o qual aumentou de 101 para 154 países (ABIEC, 2020). O mercado interno absorveu $76,3 \%$ da produção e registrou um consumo per capita de carne bovina de $38,37 \mathrm{~kg} /$ habitante/ano (ABIEC, 2020).

O estado do Tocantins é uma das unidades da federação que se destaca pela sua tradição na produção de bovinos de corte, especialmente a pasto, apresentando um efetivo de mais de 8 milhões de cabeças bovinas em 2019, o que corresponde a quase $4 \%$ do total nacional e uma evolução do rebanho de mais de 9\% nos últimos 10 anos (ABIEC, 2020). O estado abateu no referido ano mais de 1 milhão de cabeças, sendo o município de Araguaína um Polo (Cluster Norte) de destaque na atividade (SIDRA, 2020).

Os resultados positivos são fruto de inovação, pesquisa e desenvolvimento, incorporação de novas tecnologias, nutrição e melhoramento genético dos rebanhos. A produtividade e a eficiência da pecuária de corte melhoraram significativamente. Entre 1990 e 2019 a produtividade da pecuária deu um salto de $169 \%$, passando de 1,6@/ha/ano para 4,3@/ha/ano (ABIEC, 2020). A produção de carne cresceu $128 \%$ nesse período com redução do uso de pastagens bem como do desmatamento de florestas para formação de pastagens, tornando a produção mais sustentável e ética (ABIEC, 2020).

Em contrapartida, pontos importantes de algumas etapas da cadeia ainda necessitam de soluções e/ou evoluções. Apesar dos resultados expostos apresentarem certa euforia para os profissionais envolvidos na cadeia da carne bovina, estes não podem servir de égide para os gargalos ainda existentes. Além da produção e produtividade da carne, é de capital importância pensar na qualidade que está diretamente relacionada com o retorno econômico da atividade (BURNS, 2019).

Nesse sentido, uma das etapas mais relevantes é o manejo pré-abate, que envolve ainda vários pontos estressores para os animais, sendo o transporte considerado o fator crítico porque compromete drasticamente o bem-estar animal (BURNS, 2019; PEÑUELA et al., 2010). Em um mundo globalizado onde o consumidor, especialmente a geração $\mathrm{Y}$, está cada vez mais conectado e interessado em saber a origem, bem como a qualidade dos produtos que consome e preocupado com bem-estar dos animais, implicações e apelos sociais são gritantes, tornando indispensável adequações dentro da cadeia produtiva (GRANDIN, 2014; SMITH e BROWER, 2012).

Conforme explicam Duarte et al. (2014), o transporte é uma etapa pré-abate que apresenta grande risco de perdas quantitativas e qualitativas na carcaça. Conforme os autores, as perdas ocorrem para produtores, frigoríficos e consumidores. Há ainda perdas por comprometimento da qualidade da carne, como a ocorrência da carne do tipo DFD (Dark, Firm, Dry), que consiste numa carne inferior por apresentar-se escuro, dura e seca (BURNS, 2019). Além do efeito DFD, há também mudança no $\mathrm{pH}$ da carne, reflexo de jejuns prolongados, desidratação, medo e outras fontes de estresse a que os animais são submetidos durante o transporte, mesmo que com todos os cuidados de manejo (BRITO, 2017; BURNS, 2019; 
GRANDIN, 2014).

O fato de o Brasil apresentar grande extensão territorial, as regiões de produção, abate e consumo serem dispersas espacialmente e a principal via de transporte ser a malha rodoviária faz com que os animais sejam transportados por longas distâncias, frequentemente em malhas rodoviárias precárias, gerando maiores custos operacionais, comprometimento do bem-estar animal e gerando prejuízos econômicos (ANDRADE et al., 2008; FRANCO, 2013; MAPA, 2016).

Um passo importante foi dado com a Resolução 675, em 21 de junho de 2017 (BRASIL, 2017). Esta "dispõe sobre o transporte de animais de produção ou de interesse econômico, de esporte, de lazer e de exposição" $\left(\right.$ Art. $1^{\circ}$ ). No Art. $3^{\circ}$ da referida Resolução, são abordados os requisitos que veículos para transporte de animais vivos devem atender. Entre eles "ser construído ou adaptado de forma a evitar o sofrimento desnecessário e ferimentos, bem como para minimizar agitação dos animais, a fim de garantir a manutenção da vida e o bemestar animal" (BRASIL, 2017). Também trata da lotação de animais, da circulação de ar, ausência de proeminências que possam provocar ferimentos, entre outros (BRASIL, 2017).

Nesse contexto, os principais questionamentos que direcionaram este estudo foram: Diante da realidade estadual e com base nos dados já expostos pela literatura científica, quais podem ser os prejuízos econômicas decorrentes do descarte de carne de carcaças bovinos no abatedouro em razão de lesões provocadas na etapa de transporte dos animais para o abate no estado do Tocantins? Os profissionais envolvidos têm conhecimento do quão impactante a etapa de transporte é para a qualidade da carne e a rentabilidade da atividade? Estes profissionais passam por alguma forma de capacitação? Visando responder a esse questionamento este estudo teve o objetivo de estimar as perdas econômicas decorrentes do descarte de lesões nas carcaças bovinas causadas pelo transporte pré-abate no estado do Tocantins.

Este artigo está estruturado em quatro seções: esta introdução, seguida pelos métodos utilizados para o desenvolvimento do estudo. $\mathrm{Na}$ terceira seção são apresentados os resultados e discussões e, por fim e não menos importante, as conclusões na quarta seção.

\section{MATERIAIS E MÉTODOS}

A pesquisa foi realizada no período de abril a novembro de 2018. A região de estudo foi o estado do Tocantins. O estado é uma região de fronteira agrícola e tem apresentado marcante vocação para o agronegócio, o que evidencia a importância da pecuária de corte para a economia e desenvolvimento do estado (ABIEC, 2020).

A pesquisa foi desenvolvida por meio das abordagens qualitativa e quantitativa. $\mathrm{O}$ método aplicado foi o dedutivo e, quanto a natureza da pesquisa, em aplicada pois visa trazer soluções de ordem prática para problemas reais. Assim se tornou necessária um estudo esmiuçado na tentativa de compreender melhor sobre as perdas econômicas decorrentes do transporte de bovinos para o abate no estado do Tocantins.

Os procedimentos utilizados para o estudo de caso foram a pesquisa bibliográfica, a pesquisa documental e entrevistas semiestruturadas, tendo sido adotado simultaneamente a observação assistemática de forma complementar às entrevistas no estudo de caso. A Tabela 1 apresenta parte da base bibliográfica que se constituiu no norte para as estimativas de perdas econômicas causadas em função do transporte de bovinos até o abate. 
Tabela 1: Estudos relatando perdas econômicos decorrentes da etapa de transporte.

\begin{tabular}{cccc}
\hline $\begin{array}{c}\mathbf{N}^{\circ} \text { de } \\
\text { animais/carcaças }\end{array}$ & $\begin{array}{c}\text { Percentual de } \\
\text { animais contundidos }\end{array}$ & Perda & Autores \\
\hline 121 & 45,5 a 100\% & $56,1 \mathrm{~kg}$ & Andrade et al. (2008) \\
\hline 209 & $88,5 \%$ & $96,2 \mathrm{~kg}$ & Andrade et al. (2009) \\
\hline 3.415 & $>60 \%$ & - & Bertolini et al. (2012) \\
\hline 198 & $33 \%$ & 190 lesões totais & Braggion e Silva (2004) \\
\hline 100 & - & - & $\begin{array}{c}\text { Chulayo; Bradley; } \\
\text { Muchenje (2016) }\end{array}$ \\
\hline 19.635 & - & $0,97 \mathrm{~kg} /$ animal & Franco (2013) \\
\hline 1.048 & $12 \%$ & $33.619,8 \mathrm{~kg}$ & Ferreira et al. (2010) \\
\hline- & - & US \$ 6,1 / cab. & $\begin{array}{c}\text { Schuwartzkopl- } \\
\text { Genswein et al. (2012) }\end{array}$ \\
\hline
\end{tabular}

Fonte: Os autores (2021)

Foi realizado o levantamento das plantas frigoríficas existentes no estado. Essa informação foi obtida por meio de entrevistas aos membros do Sindicato das Indústrias Frigoríficas de Carnes Bovinas, Suínas, Aves, Peixes e Derivados do Estado do Tocantins SINDICARNES, e também da unidade local do Ministério da Agricultura, Pecuária e Abastecimento - MAPA localizado no município de Palmas, capital do Tocantins.

Em seguida foram realizadas entrevistas semiestruturadas com os grupos de profissionais das etapas de embarque na propriedade, transporte, desembarque e abate. Foi realizado o contato prévio com os entrevistados por telefone ou e-mail. $\mathrm{Na}$ ocasião, os autores se identificaram, apresentaram a pesquisa e realizaram o convite para o profissional contatado em participar da pesquisa, reportando a relevância do estudo e nas contribuições que este poderia trazer. Para os entrevistados que aceitaram participar, foi feita a leitura e assinatura de um Termo de Consentimento Livre e Esclarecido (TCLE), garantindo o sigilo e a segurança para participantes e pesquisadores.

$\mathrm{O}$ processo de amostragem adotado foi o sequencial e orientado, onde um entrevistado fazia a indicação de outro contato que poderia fornecer mais informações relevantes à pesquisa. Os entrevistados perfizeram um total de 21 sendo: Dois pecuaristas, um vaqueiro, três motoristas de caminhão do tipo "truck", dez representantes dos frigoríficos com Selo de Inspeção Federal (SIF), um veterinário e quatro zootecnistas.

Após construir uma base documental e bibliográfica com dados secundários sobre $\mathrm{o}$ número de animais abatidos, valor da arroba atualizado para o estado do Tocantins, condições de manutenção das rodovias, nível de perdas encontradas em carcaças bovinas decorrentes do transporte relatadas na literatura científica e localização dos frigoríficos com Selo de Inspeção Federal - SIF, foram realizados os demonstrativos de prejuízos financeiros seguindo o modelo proposto por Ferreira et al. (2010).

A adaptação no modelo ocorreu com relação ao peso das lesões, onde foram atribuídos diferentes valores hipotéticos de peso para as lesões baseados nos dados encontrados por diferentes pesquisas relacionadas à problemática. Estimativas do impacto das perdas econômicas à cadeia da carne bovina foram calculadas considerando os seguintes valores de lesões removidas por animal: $0,1 \mathrm{~kg} ; 0,2 \mathrm{~kg} ; 0,3 \mathrm{~kg}$; 0,4 
$\mathrm{kg} ; 0,5 \mathrm{~kg} ; 1,0 \mathrm{~kg} ; 1,5 \mathrm{~kg} ; 2,0 \mathrm{~kg} ; 3,0 \mathrm{~kg}$. Com o intuito de enriquecer a análise e proporcionar uma reflexão mais realista foram estabelecidos, também, diferentes percentuais de animais contundidos sobre o total de bovinos abatidos no estado, ou seja, 1,03 milhões de cabeças. Para isso foram adotados percentuais hipotéticos de animais contundidos de 10, 20, 30, 40, 50 e 60\%, que são percentuais comumente relatados em pesquisas na literatura científica nacional e, especificamente, estadual, conforme exposto no Quadro 1.

\section{RESULTADOS E DISCUSSÃO}

No que concerne à metodologia, constatou-se que os procedimentos metodológicos adotados para desenvolver o estudo e alcançar o objetivo proposto foram adequados. Após a coleta dos dados secundários (pesquisa bibliográfica e documental) que balizaram o estudo e direcionaram as entrevistas, seguiu-se a coleta de dados primários. Inicialmente, foram entrevistados profissionais do setor (médicos veterinários e zootecnistas) para conhecer a realidade experimentada por estes em campo e elencar informações relevantes e contatos de outros profissionais para as demais entrevistas. O próximo passo consistiu nas entrevistas aos demais profissionais localizados e que aceitaram participar da pesquisa.

Os profissionais (Médicos Veterinários e zootecnistas) apresentaram conhecimento acerca da relevância dos cuidados e manejo de bovinos no pré-abate, especialmente no que se refere ao transporte. Mas segundo o entrevistado 4, "não é possível estar presente em todas as etapas pelas quais os animais são submetidos para tentar garantir manejo adequado". Já o entrevistado 3 ressaltou a importância da capacitação dos condutores dos veículos "para que eles entendam que não se trata de 'dozinha' dos animais, mas de prejuízos econômicos”.

Os motoristas entrevistados afirmaram ter escutado recomendações sobre essa "questão dos problemas do transporte dos animais", mas não passaram por cursos de capacitação e nem de atualização. Para o entrevistado 11, “já tá tudo ok, o caminhão é seguro para os animais, tá com revisão em dia". Todavia, foi observado que haviam parafusos expostos, tábuas com lascas que poderiam ferir os animais, piso escorregadio, entre outros pontos. Em síntese, os motoristas minimizam os problemas existentes ou atribuem aos custos a ocorrência deles considerando inviável adotar menores densidades, realizar uma manutenção adequada nos veículos ou mesmo modificações para reduzir a ocorrência de lesões.

A montante da cadeia, se observa ainda um tradicionalismo por parte dos produtores e seus funcionários na forma de manejar os animais. A mentalidade que ainda predomina é a de que "o animal já vai ser abatido mesmo, então tanto faz". Mas a literatura científica deixa claro que os problemas decorrentes do comprometimento do bem-estar dos animais são muito mais profundos e relevantes (GRANDIN, 2014).

Os dados produzidos com a pesquisa evidenciaram que existe uma localização estratégica dos frigoríficos com SIF no estado do Tocantins, conforme pode ser observado na Figura 1. Nas entrevistas os representantes de frigoríficos confirmaram essa observação, demonstrando ainda conhecimento acerca da importância da etapa de transporte dos animais para o abate e seu impacto sobre a qualidade da carne e rendimento de carcaça. Apenas um representante de frigorífico não demonstrou atenção semelhante ao tema. 


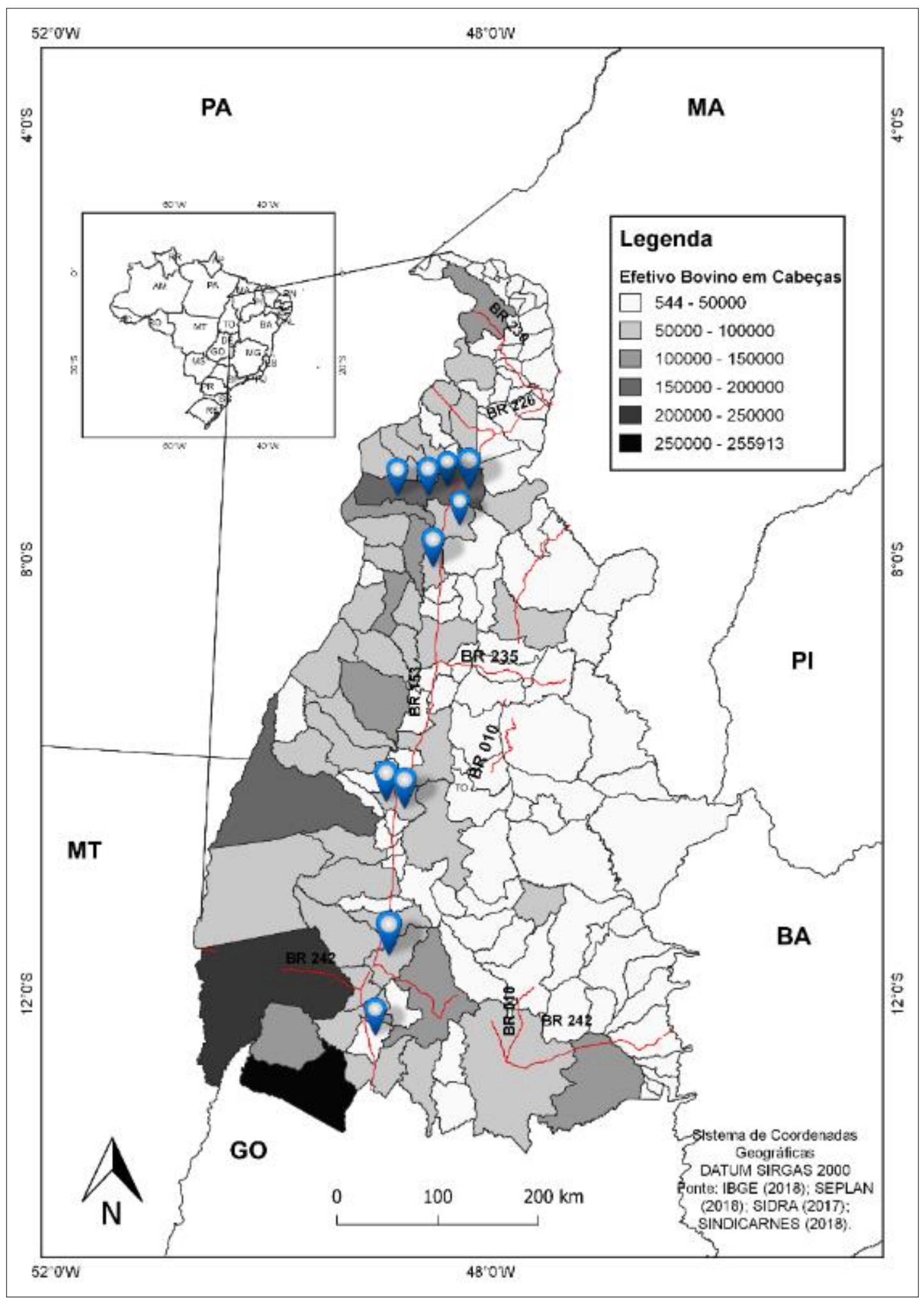

Figura 1: Mapa graduado do efetivo bovino dos municípios tocantinenses, rodovias federais (BR) do estado e localização dos frigoríficos com inspeção federal (SIF). Fonte: Elaborado pelos autores a partir de banco de dados SEPLAN (2018); SIDRA (2018); SINDICARNES (2018); MAPA (2018). 
Os frigoríficos estão localizados em municípios que têm um efetivo bovino expressivo e/ou próximos de outros municípios que possuem um efetivo importante dessa espécie animal (ver Figura 1). O rebanho bovino do estado está mais concentrado na região oeste e ao extremo sul do estado. Provavelmente, isso ocorre devido às características climáticas, pedológicas e logísticas dessas regiões.

Com relação a malha rodoviária, foi constatado que os frigoríficos também estão localizados próximos à BR 153, que corta praticamente todo o estado de norte a sul. Os municípios que possuem frigoríficos com SIF são aqueles por onde a BR 153 passa dentro ou próximo ao município, como Alvorada (1), Gurupi (1), Paraíso (2), Colinas (1), Nova Olinda (1) e Araguaína (4). Pode-se observar que o município de Araguaína possui o maior número de plantas frigoríficas. A cidade apresenta um rebanho bovino expressivo e está próxima de grandes regiões produtoras de bovinos de corte, tanto no estado do Tocantins quanto no estado do Pará, cuja pecuário de corte é reconhecida a nível nacional.

Todas as plantas frigoríficas com SIF no estado se comprometem a transportar os animais da propriedade até o frigorífico para o abate, seja com veículo da próprio ou terceirizado. Geralmente, os frigoríficos limitam o transporte dos animais a um raio de 100 a $150 \mathrm{~km}$ de distância do estabelecimento, conforme relatado pelos entrevistados. Porém, resultados contrários foram diagnosticados por Burns (2019), onde constatou que algumas fazendas ficam a mais de $300 \mathrm{~km}$ dos frigoríficos. Isso se deve ao fato do transporte ser oneroso. Dessa forma, fica evidente que a preocupação existente em torno do transporte não é em função primordialmente do bem-estar animal, gira mais em torno de aspectos econômicos do que por valores éticos.

Apesar de Ferreira et al. (2010) não terem observado densidade superior a $550 \mathrm{Kg} / \mathrm{m}^{2}$ nas gaiolas com bovinos que chegaram em frigorífico no município de Araguaína/TO, os autores relataram a precariedade da maior parte dos veículos $(78,7 \%)$, o que agudizam o problema da ocorrência de lesões nas carcaças.

Apesar disso, o fato dos frigoríficos transportarem os animais em distâncias menores (até $150 \mathrm{~km}$ ) é extremamente positivo para, possivelmente, reduzir a ocorrência de estresse $\mathrm{e}$ lesões nos animais transportados para o abate. Burns (2019) constatou no norte do estado do Tocantins que os bovinos transportados por longas distâncias $(>300 \mathrm{~km})$ apresentaram alta atividade da creatina quinase, o que infere ocorrência de estresse e até mesmo lesões físicas. Também foi observado que as fêmeas são mais reativas ao estresse a que são expostas durante o transporte para o frigorífico (BURNS, 2019).

Com relação ao veículo mais utilizado no transporte de bovinos destinados ao abate, o tipo "truck" foi o que prevaleceu. Esse resultado está de acordo com o encontrado por Bertoloni et al. (2012), pois conforme os autores o "truck" é o mais utilizado no Brasil para o transporte de bovinos destinados a abate, sendo que possui capacidade para transportar 18 animais adultos. Resultado semelhante foi encontrado por Franco (2013) que também observou ser o "truck" o mais utilizado para essa finalidade.

O uso desse veículo é positivo uma vez que Bertoloni et al. (2012) relataram que encontraram menos lesões recentes em lotes de animais transportados em caminhão tipo truck (66\%) quando comparado a lotes conduzidos em veículos como a carreta baixa $(79 \%)$ e carreta tipo double deck (100\%) para distância de 75 a $130 \mathrm{~km}$. Além disso, os autores destacaram que as lesões ocorreram com maior frequência nos cortes nobres, como contrafilé, causando prejuízos mais importantes.

O condutor do veículo deve ter conhecimentos a respeito do comportamento da espécie transportada, do cuidado na condução do veículo em curvas e da ocorrência de declividade para que os animais não caiam e/ou deitem 
provocando lesões graves e/ou até mesmo fatais e refletindo em prejuízos éticos e econômicos à cadeia da carne (BURNS, 2019; FERREIRA et al., 2010). Por meio das entrevistas constatou-se que ainda prevalece a visão do animal apenas como "carga", sendo que o ideal é que houvesse a consciência de que são no mínimo "carga viva" e como tal sentem sede, fome, medo, dor, se relacionam socialmente com os demais e que necessitam de alguns cuidados que vão além de uma carga convencional.

Os motoristas dos veículos responsáveis pelo transporte dos bovinos até o abate não apresentam uma formação específica acerca do cuidado com os animais, da forma ideal de condução para minimizar a ocorrência de prejuízos econômicos e ao bem-estar dos animais. Apesar da distância não ser grande (até $150 \mathrm{~km}$ ) o manejo, as condições da malha rodoviária e a estrutura do veículo são extremamente importantes para evitar o estresse e a ocorrência de lesões.

Além disso, sabe-se que em determinadas condições ocorrem o transporte de animais em uma distância superior a relatada pelos estabelecimentos, especialmente quando se trata de um número maior de animais, o que dilui o custo do frete. Também foi observado uma deficiência por parte dos motoristas com relação ao conhecimento dos impactos do transporte na qualidade do produto final, a carne.

O manejo inadequado, reduções bruscas da velocidade, execução de curvas com o veículo em velocidade elevada provocam ferimentos nos animais, aumentando ainda mais o sofrimento durante o transporte, que por si só já é um dos eventos mais estressantes na vida de uma animal, como confirma Braggion e Silva (2004). Eniolorunda et al. (2009) consideram que não existe como anular a existência de estresse nos animais durante o transporte, mas é possível minimizar por meio de uma normatização que sirva de norte para os procedimentos relacionados ao transporte destes.
Outro ponto que merece destaque é com relação a estrutura do veículo. Para evitar a ocorrência de contusões e ferimentos em geral, é necessário que o veículo apresente estrutura adequada, sem proeminências que possam ferir os animais. Todavia, os caminhões "truck" ainda possuem objetos perfurantes como pregos muito expostos, piso que não fornece aderência suficiente para evitar escorregões, portas que ferem facilmente os animais, gaiola muito fechada ou muito aberta. Assim se verifica que existe um caminho relativamente grande para a adequação completa dos veículos a Resolução 675, citada anteriormente (BRASIL, 2017).

A capacidade de abate das plantas frigoríficas contatadas ficou entre 300 e 750 cabeças/dia, segundo os entrevistados. Os animais abatidos podem ser oriundos de todo o estado e até de estados vizinhos, todavia comumente ocorre o abate de animais localizados mais próximos. Entre as dificuldades no transporte que foram informadas pelos entrevistados, as chuvas torrenciais frequentes que ocasionaram queda de pontes nas zonas rurais, atoleiros e buracos nas estradas pavimentadas ou que levam a um atraso na viagem, foram as mais citadas.

Foram relatados casos de queda de ponte em razão do grande volume de água de rios, córregos entre outros, levando os animais a ficarem longos períodos dentro do veículo sem água e comida, sem descanso, trazendo sérios prejuízos devido a quedas, lesões, desidratação e perda de peso. Consequentemente, esses eventos fazem com que o tempo de transporte se estenda além do habitual, agravando o problema do comprometimento do bem-estar dos animais, levando a maiores prejuízos de ordem econômica.

Em relação às estimativas de perdas econômicas decorrentes da etapa de transporte de bovinos para o abate, os valores encontrados foram alarmantes. Considerando que o valor médio da arroba no estado do Tocantins em 
janeiro de 2021 foi $\mathrm{R} \$ 262,00$ (SCOT CONSULTORIA, 2021), o número de animais abatidos foi de pouco mais de um milhão de cabeças e atribuindo diferentes percentuais de ocorrência de lesões bem como do peso das mesmas, estimou-se prejuízos econômicos que variaram de $\mathrm{R} \$ 179.907,00$ a $\mathrm{R} \$ 32.383 .200,00$.

$\mathrm{O}$ que se verifica é que tanto as estimativas subestimadas quanto as superestimadas são relevantes do ponto de vista financeiro, trazendo prejuízos econômicos aos produtores. Por isso, são indicativos de perdas econômicas para frigoríficos e até mesmo consumidores, apesar de ser de difícil mensuração os impactos a estes últimos. A Tabela 2 mostra os valores referentes as estimativas de perdas relacionadas a má qualidade do transporte de bovinos até o abatedouro.

Ferreira et al. (2010) constataram um prejuízo econômico de $\mathrm{R} \$ 116.550,00$ em estudo conduzido em frigorífico com SIF no município de Araguaína/TO. Levando-se em conta que o valor da arroba do boi gordo aumentou consideravelmente e o estudo incluiu uma parcela pequena do rebanho abatido e em apenas uma planta frigorífica, é possível inferir que de fato os prejuízos anuais para a cadeia e, especialmente, aos produtores é expressivo.

Há ainda outros agravantes como a qualidade da malha rodoviária tocantinense. Levando-se em consideração a ineficiente manutenção da malha rodoviária do estado, uma vez que quase $60 \%$ foram classificadas como regular, conforme dados da CNT (2017) e apenas $35,8 \%$ estão em boa ou ótima condição (o restante estão em más condições de manutenção), o risco do transporte trazer efeitos deletérios aos animais é ainda maior, reforçando a hipótese de que as estimativas aqui expostas reflitam a realidade da cadeia da carne no Tocantins.

Brito (2017) encontrou diferença significativa entre os animais transportados em vias pavimentadas ou não pavimentadas. Os resultados da pesquisa mostraram que mesmo em vias pavimentadas, quanto maior a distância percorrida maior a ocorrência de lesões. Quando essa distância foi maior que $50 \mathrm{~km} 66,7 \%$ dos animais apresentaram lesões, enquanto nos conduzidos por menos de $50 \mathrm{~km}$ o percentual foi de 18,4\% (BRITO, 2017). Em estudo conduzido por Braggion e Silva (2004) no Pantanal SulMato-Grossense, $\quad 100 \%$ das carcaças apresentaram lesão. Já Bertoloni et al. (2012) verificaram uma média de ocorrência de lesões em 75,8\% dos animais. Andrade et al. (2008) também encontraram resultados próximos, onde foram avaliadas 121 carcaças e 102 apresentaram lesões, ou seja, $84,3 \%$ das carcaças.

Adicionalmente, se tem também uma extensa malha rodoviária sem pavimentação. Apesar dos frigoríficos estarem localizados próximos à $\mathrm{BR} 153$, o percurso até estes envolvem trechos sem pavimentação nas zonas rurais dos municípios, pois o acesso a grande maioria das fazendas produtoras de gado de corte depende do tráfego por estradas de terra cujas condições comumente são precárias, especialmente no período chuvoso.

Nestas condições apresentadas, mesmo que o transporte seja por pequenas distâncias, o risco de contusões nos animais é elevado. Uma vez que os movimentos realizados pelo veículo para escapar de buracos, as frenagens, e a movimentação atípica e constante em razão das irregularidades da estrada fazem com que os animais se desequilibrem com frequência e assim trombem uns nos outros e na gaiola do veículo, o que leva a ocorrência de hematomas que as vezes só serão vistos após o abate, na etapa do toalete. As estimativas são apresentadas na Tabela 2. 
Tabela 2: Estimativas de prejuízos em função do tamanho das lesões para dois valores do preço da arroba, com base no número de animais abatidos no estado

\begin{tabular}{|c|c|c|c|c|c|c|}
\hline \multirow{2}{*}{$\begin{array}{l}\text { Peso lesão/ } \\
\text { cab }\end{array}$} & \multicolumn{6}{|c|}{ Percentual de carcaças com lesões, hematomas e/ou contusões } \\
\hline & $10 \%$ & $20 \%$ & $30 \%$ & $40 \%$ & $\mathbf{5 0 \%}$ & $60 \%$ \\
\hline 0,10 & $\mathrm{R} \$ 179.907,00$ & $\mathrm{R} \$ 359.813,00$ & $\mathrm{R} \$ 539.720,00$ & $\mathrm{R} \$ 719.626,00$ & $\mathrm{R} \$ 899.533,00$ & $\mathrm{R} \$ 1.079 .440,00$ \\
\hline 0,20 & $\mathrm{R} \$ 359.813,00$ & $\mathrm{R} \$ 719.627,00$ & $\mathrm{R} \$ 1.079 .440,00$ & $\mathrm{R} \$ 1.439 .253,00$ & $\mathrm{R} \$ 1.799 .066,00$ & $\mathrm{R} \$ 2.158 .880,00$ \\
\hline 0,30 & $\mathrm{R} \$ 539.720,00$ & $\mathrm{R} \$ 1.079 .440,00$ & $\mathrm{R} \$ 1.636 .627,00$ & $\mathrm{R} \$ 2.158 .880,00$ & $\mathrm{R} \$ 2.698 .600,00$ & $\mathrm{R} \$ 3.238 .320,00$ \\
\hline 0,40 & $\mathrm{R} \$ 719.627,00$ & $\mathrm{R} \$ 1.439 .253,00$ & $\mathrm{R} \$ 2.158 .880,00$ & $\mathrm{R} \$ 2.878 .507,00$ & $\mathrm{R} \$ 3.598 .133,00$ & $\mathrm{R} \$ 4.317 .760,00$ \\
\hline 0,50 & $\mathrm{R} \$ 899.533,00$ & $\mathrm{R} \$ 1.799 .066,00$ & $\mathrm{R} \$ 2.798 .600,00$ & $\mathrm{R} \$ 3.598 .133,00$ & $\mathrm{R} \$ 4.497 .667,00$ & $\mathrm{R} \$ 5.397 .200,00$ \\
\hline 1,00 & $\mathrm{R} \$ 1.799 .067,00$ & $\mathrm{R} \$ 3.598 .133,00$ & $\mathrm{R} \$ 5.397 .200,00$ & $\mathrm{R} \$ 7.196 .266,00$ & $\mathrm{R} \$ 8.995 .333,00$ & $\mathrm{R} \$ 10.794 .400,00$ \\
\hline 1,50 & $\mathrm{R} \$ 2.698 .600,00$ & $\mathrm{R} \$ 5.397 .200,00$ & $\mathrm{R} \$ 8.095 .800,00$ & $\mathrm{R} \$ 10.794 .400,00$ & $\mathrm{R} \$ 13.493 .000,00$ & $\mathrm{R} \$ 16.191 .600,00$ \\
\hline 2,00 & $\mathrm{R} \$ 3.598 .133,00$ & $\mathrm{R} \$ 7.196 .267,00$ & $\mathrm{R} \$ 10.794 .400,00$ & $\mathrm{R} \$ 14.392 .533,00$ & $\mathrm{R} \$ 17.990 .667,00$ & $\mathrm{R} \$ 21.558 .800,00$ \\
\hline 3,00 & $\mathrm{R} \$ 5.397 .200,00$ & $\mathrm{R} \$ 10.784 .400,00$ & $\mathrm{R} \$ 16.191 .600,00$ & $\mathrm{R} \$ 21.588 .800,00$ & $\mathrm{R} \$ 26.986 .000,00$ & $\mathrm{R} \$ 32.383 .200,00$ \\
\hline
\end{tabular}

Fonte: Estimativa realizada pelos autores segundo a modelo adotado por Ferreira et al. (2010) 
Andrade et al. (2008) relataram maior quantidade de hematomas em carcaças oriundas de lotes que foram transportados em estradas não pavimentadas. No lote VI que percorreu maiores distâncias e em rodovias não pavimentadas, $100 \%$ dos animais apresentaram algum tipo de lesão e estas levaram a uma média de remoção de $1,0 \mathrm{~kg}$ de carne por animal. Os autores observaram que $84,3 \%$ das carcaças apresentaram lesões gerando uma média de remoção de $0,5 \mathrm{~kg}$ por animal. Além do tipo de caminhão, o tipo de piso, densidade animal transportada, a forma de condução do veículo são outros fatores importantes a serem observados no transporte dos animais até o abatedouro.

Eniolorunda et al. (2009, p.224, tradução nossa) explicam que durante o transporte os animais são expostos a diversas fatores estressores, o que "constitui uma quebra nos estereótipos dinâmicos do animal, muitas vezes acompanhados de ruído excessivos [...]" além de agressões advindas de pessoas envolvidas no manejo de embarque, transporte e desembarque dos animais.

Considerando o cenário existente atualmente no estado do Tocantins com relação à malha rodoviária, condições de veículos, falta de capacitação dos condutores e efetivo expressivo de bovinos abatidos anualmente, verifica-se que as perdas econômicas estimadas são possíveis. $\mathrm{Na}$ literatura existem evidências de níveis de perdas nas carcaças, com consequentes prejuízos financeiros, dentro de condições similares às encontradas no estado utilizado como referência para esse estudo (ANDRADE et al., 2008; ANDRADE et al., 2009; BERTOLINI et al., 2012; BRAGGION e SILVA, 2004; FRANCO, 2013; FERREIRA et al., 2010; TSEIMAZIDES, 2016).

Em revisão acerca do transporte de bovinos, Schwartzkopf-Genswein et al. (2012) relataram que perdas pela ocorrência de cortes escuros foram de US \$6,08/cabeça e hematomas US \$1,30 a 4,03/cabeça. Carcaças bovinas passam pelo chamado toalete nos frigoríficos, onde são removidos tecidos que não estão aptos ao consumo humano, como regiões que apresentem hematomas. Carne com lesões não são aceitas comercialmente, sendo impróprias para o consumo além da vida de prateleira ser reduzida devido à rápida decomposição (CIVEIRA et al., 2006 apud ANDRADE e COELHO, 2011).

\section{Como comentou Tseimazides (2016),} grandes melhorias no manejo de bovinos para o abate são observadas, mas é preciso buscar constantemente melhorias para tornar a cadeia produtiva mais rentável e ética, garantindo segurança e qualidade aos consumidores. Para que exista uma evolução, os envolvidos no transporte animal precisam de informação e conhecimento adequados pois "há uma distância entre geração de conhecimento e sua aplicação" (DUARTE et al., 2014, p.145).

Vale ressaltar que além das perdas evidentes por hematomas, contusões e outras lesões que são visualizadas e descartadas no momento do toalete, outros prejuízos podem ser identificados como alterações no $\mathrm{pH}$, vida de prateleira, cor e textura da carne ou mesmo a ocorrência da carne DFS. Dependendo da forma de contrato e das perdas ocasionadas pelo manejo pré-abate, especialmente no transporte dos animais para o frigorífico, os produtores "pagarão" pelos prejuízos econômicos. Dependendo das condições o frigorífico acabará sofrendo uma parte dos prejuízos. Na ponta final da cadeia, o consumidor poderá adquirir um produto com as qualidades organolépticas alteradas, culpabilizando possivelmente os produtores, a indústria ou mesmo pondo sob suspeita a segurança da ingestão da carne vermelha em dietas saudáveis.

Para o produtor a perda ocorre devido a retirada de lesões, reduzindo o rendimento de carcaça. No caso do frigorífico, essas perdas são identificadas apenas no momento do processamento. Já no caso do consumidor, as perdas podem ser percebidas apenas no momento do preparo da carne, pois podem ser detectadas pequenas lesões além de perdas qualitativas decorrentes do estresse, medo e jejum prolongado que provocam alterações no $\mathrm{pH}$ da carne e esgotamento da reserva de glicogênio, fatores que comprometem as qualidades organolépticas da carne e sua vida de prateleira (durabilidade) (DUARTE et al., 2014). 
Percebe-se que em algum nível todos sofrem as consequências do manejo tradicional, desprovido de valores éticos e de preocupação com o bem-estar animal e com a consciência, apelos e exigências do consumidor. Ferreira et al. (2010) destacam que todos os profissionais envolvidos na atividade necessitam de capacitação para que hajam maiores evoluções nesse sentido e, no que se refere a este estudo, para os condutores de veículos, isso se justifica para a conscientização do quão impactante essa etapa é para a cadeia, embora os motoristas não percam ou ganhem diretamente em termos financeiros.

\section{CONCLUSÕES}

O objetivo deste estudo foi alcançado e foram estimadas as perdas econômicas decorrentes do descarte de lesões nas carcaças bovinas causadas pelo transporte pré-abate no estado do Tocantins.

A metodologia adotada foi adequada para atingir o objetivo do estudo, possibilitando obter dados primários e secundário sobre o assunto pesquisado. Todavia, ressalta-se que estudos futuros são necessários para buscar caminhos para a superação do tradicionalismo no manejo dos bovinos para o abate, incluindo não apenas o transporte, mas também condução e separação dos animais nos currais, embarque, transporte e desembarque no destino final. É de importância capital que pesquisas sejam realizadas em prol de elencar políticas públicas e cursos de capacitação estratégicos para a mudança de mentalidade dos profissionais da cadeia da carne bovina, visto que melhorias podem ser implementadas apenas com mudança de comportamento e parte delas independe de investimentos e não é onerosa.

As estimativas apontaram que provavelmente a cadeia tem sofrido prejuízos econômicos na ordem de milhões de reais anualmente. Embora existam fatores de difícil correção, há aqueles que são totalmente viáveis e simples de serem postos em prática e que trariam um impacto positivo.

Também é preciso fornecer uma formação adequada aos profissionais que trabalham diretamente com os animais no embarque, transporte e desembarque, especialmente aos motoristas de caminhões boiadeiros ("truck"), devido ao impacto que estes tem sobre a qualidade da carne ao final do processo. É muito importante que os profissionais que trabalham nesse setor tenham consciência da influência dos seus atos na qualidade de vida de bovinos no pré-abate e o quanto esta etapa é importante do ponto de vista ético (bem-estar animal) e econômico.

A pecuária de corte sofre prejuízos consideráveis em razão de falhas na etapa de transporte dos bovinos até o abate e o cenário atual do estado apresenta-se de maneira a perpetuar essas perdas pelos próximos anos, caso não haja uma mudança mais expressiva no modelo atual de transporte animal.

Apesar de serem observadas melhorias nas condições de transportes, malha rodoviária e rural no decorrer das últimas décadas, mudanças são necessárias como a ampliação da pavimentação, manutenção adequada das vias atualmente pavimentadas. Isso refletirá em menor tempo de transporte, redução do estresse para o condutor do veículo e animais transportados, diminuição de perdas por remoção de tecidos lesionados e melhorias na qualidade da carne produzida.

Com relação aos caminhões, a Resolução 675 provavelmente contribuirá positivamente, mas levará um espaço de tempo para que os efeitos sejam perceptíveis na melhora dos veículos para transportar os animais, reduzindo a ocorrência de lesões.

Por fim, é preciso entronizar na cadeia que o consumidor é o responsável por determinar a demanda e ao atendê-la haverá o retorno financeiro. Além disso, investimentos em marketing digital apresentando aos consumidores os benefícios do consumo da carne bovina e como os animais são criados, transportados e abatidos de maneira ética e humanitária, tem sido uma tendência mundial pois cada vez mais na era da conectividade os consumidores tem se preocupado com a origem dos produtos que consome e em como o mesmo é 
produzido.

\section{FINANCIAMENTO}

A primeira autora agradece a Coordenação de Aperfeiçoamento de Pessoal de Nível Superior (CAPES) pela concessão de bolsa de pesquisa ao nível de mestrado. $\mathrm{O}$ presente trabalho foi realizado com apoio da Coordenação de Aperfeiçoamento de Pessoal de Nível Superior - Brasil (CAPES) - Código de Financiamento 001.

\section{REFERÊNCIAS BIBLIOGRÁFICAS}

Andrade, E. N.; Silva, R. A. M. S. \& Roça, R. O. (2009). Manejo pré-abate de bovinos de corte no Pantanal, Brasil. Archivos de Zootecnia 58 (222): 301-304.

Andrade, J. \& Coelho, H. E. (2011). Ocorrência de contusões em carcaças bovinas e suas perdas econômicas. Cadernos de Pós-Graduação da FAZU 1:1-6.

Andrade, E.N.; Silva, R.A.M.S.; Roça, R.O.; Silva, L.A.C.; Gonçalves, H.C. \& Pinheiro, R.S.B. (2008). Ocorrência de lesões em carcaças de bovinos de corte no Pantanal em função do transporte. Ciência Rural, 38(7), 19911996. https://doi.org/10.1590/S0103$\underline{84782008000700030 .}$.

ABIEC. (2020). BeefReport 2020: Perfil da pecuária no Brasil. Brasil. Disponível em: http://abiec.com.br/publicacoes/beef-report-2020/.

Bertoloni, W.; Silva, J.K.; Abreu, J.S. \& Andreolla, D.L. (2012). Bem-estar e taxa de hematomas de bovinos transportados em diferentes distâncias e modelos de carroceria no estado do Mato Grosso Brasil. Revista Brasileira de Saúde e Produção Animal, 13(3), $850-$

859. https://doi.org/10.1590/S151999402012000300022.
Braggion, M. \& Silva, R. A. M. S. (2004). Quantificação de lesões em carcaças de bovinos abatidos em frigoríficos no Pantanal Sul-MatoGrossense. Comunicado Técnico 45 (EMBRAPA).

Brito, E.F. (2017). Lesões traumáticas em carcaças bovinas associadas ao pré-abate na microrregião de Araguaína, Tocantins: fatores principais e variabilidade espacial (Tede de doutorado). Programa de Pós-Graduação em Ciência Animal Tropical, Universidade Federal do Tocantins, câmpus Araguaína, TO, Brasil p. 70.

Burns, L.V. (2019). Efeito da distância de transporte e condições climáticas sobre os indicares fisiológicos de bem-estar dos bovinos (Tese de doutorado). Programa de pós-Graduação em Ciência Animal Tropical, Universidade Federal do Tocantins, câmpus Araguaína, TO, Brasil p. 91.

CNT. (2017). Anuário CNT dos Transportes: Estatísticas consolidadas 2017. Brasil. Disponível em: https://anuariodotransporte.cnt.org.br/2017/.

Duarte, J. S., Biazolli, W. \& Honorato, C. A. (2014). Perdas econômicas devido ao manejo pré-abate: bem-estar animal. Comunicação \& Mercado 3 (7): 144-156.

Eniolorunda, O.O.; Fashina, O.E. \& Aro, O.O.. (2009). Adaptive physiological response to load time stress during transportation of cattle in Nigeria. Archivos de Zootecnia, 58(222), 223-230.

Ferreira, J. L.; Cavalcante, T.V.; Marinho, J.P.; Lopes, F.B. \& Minharro, S. (2010). Influência do manejo pré-abate na produção de carne bovina no município de Araguaína, Tocantins. Revista Científica Eletrônica de Medicina Veterinária 15.

Franco, M.R. (2013). Caracterização do transporte rodoviário de bovinos de corte e efeitos no bemestar animal e na qualidade as carcaças 
(Dissertação de mestrado). Universidade Estadual Paulista Júlio de Mesquita Filho, Faculdade de Ciências Agrárias e Veterinárias, Jaboticabal, SP, Brasil p. 72.

Grandin, T. (2014). Animal welfare and society concerns finding the missing link. Meat Science, 98 (3): 461-469.

https://doi.org/10.1016/j.meatsci.2014.05.011.

MAPA. (2016). Bem-estar animal no transporte marítimo ou fluvial de animais vivos: panorama da atividade no Brasil e na Espanha. Diálogos setoriais, União Europeia Brasil, Brasília. Disponível em: $\quad$ https://www.gov.br/agricultura/ptbr/assuntos/boas-praticas-e-bem-estaranimal/arquivos-publicacoes-bem-estaranimal/TrabalhofinalFITO009.pdf.

MAPA. (2018). Relação de estabelecimentos: Frigoríficos com Selo de Inspeção Federal (SIF) no estado do Tocantins 2018. Tocantins, Brasil. Disponível em: https://www.gov.br/agricultura/ptbr/assuntos/inspecao/produtos-animal/sif/relatoriossif-para-exportacao/tocantins.

Peñuela, M.H.R.; Velásquez, L.F.U. \& Valencia, J.A.S. (2010). El transporte terrestre de bovinos y sus implicaciones em el bienestar animal: revisión. Biosalud 9 (2): 67- 82.

\section{SCOT CONSULTORIA. (2021). Cotações - Boi}

Gordo: Mercado físico - 08/01/2021. Disponível

em:

https://www.scotconsultoria.com.br/cotacoes/boigordo/.

Schwartzkopf-Genswein, K. S.; Faucitano, L.; Dadgar, S.; Shand, P.; González, L.A. \& Crowe, T.G. (2012). Road transport f cattle, swine and poultry in North America and its impact on animal welfare, carcass and meat quality: A review. Meat Science 92(3):

227-243.
SEPLAN. (2018). Bases vetoriais. Governo do Estado do Tocantins. Disponível em: http://www.sefaz.to.gov.br/seplan/.

SIDRA (2021). SIDRA 2021. Brasil. Disponível em: https://sidra.ibge.gov.br/home/ipca/brasil.

SINDICARNES. (2018). Quem somos. Palmas, TO. Disponível em: http://www.sindicatodaindustria.com.br/sindicarnest o/quemsomos/.

Smith, K.T. \& Brower, T.R. Longitudinal study of green marketing strategies that influence millennials. Journal of Strategic marketing 20(6): 535-551. https://doi.org/10.1080/0965254X.2012.711345

Tseimazides, S. P. (2016). Efeito do manejo préabate de bovinos no bem-estar e qualidade da carcaça. (Tese de doutorado). Universidade Estadual Paulista - UNESP, Câmpus de Jaboticabal, Jaboticabal, SP, Brasil p. 56.

https://doi.org/10.1016/j.meatsci.2012.04.010 